\title{
Marital Status and Health of the Mother as Risk Factors for Premature Birth in Pleven, Bulgaria
}

\author{
Mariela Stefanova Kamburova \\ Stela Ludmilova Georgieva ${ }^{2}$ \\ Medical University - Pleven \\ Medical University - Pleven
}

\author{
Manolya $\mathrm{Un}^{3}$ \\ Medical University - Pleven
}

\begin{abstract}
Premature birth is associated with increased infant mortality, short and long-term negative effects on health and additional costs for care. It is a major public health problem worldwide. Because marital status and the health of the mother directly effect the incidence of birth, it is an important area of research. The aim of study was to explore the impact of these factors in premature births in Pleven, Bulgaria.
\end{abstract}

\section{Keywords}

Premature Birth • Marital Status • Mothers' Health • Risk Factors

\footnotetext{
* This paper was revised after being presented at the International Journal of Health Administration and Education Congress (Sanitas Magisterium), Istanbul, Turkey, March 28-29, 2015. Mariela Kamburova conceived, guided the study and drafted the manuscript. Stela Georgieva revised the manuscript. Manolya Un presented the results in the International Journal of Health Administration and Education Congress. All authors approved the final version.

1 Correspondence to: Mariela Stefanova Kamburova, Department of Public Health Sciences, Faculty of Public Health, Medical University - Pleven, Bulgaria. Email: mariela_kamburova@yahoo.com

2 Department of Public Health Sciences, Faculty of Public Health, Medical University- Pleven, Bulgaria. Email: georgieva_sl@yahoo.com

3 Faculty of Medicine, Medical University - Pleven, Bulgaria. Email: manolyaun@gmail.com
}

Citation: Kamburova, M. S., Georgieva, S. L. \& Un, M. (2016). Marital status and health of the mother as risk factors for premature birth in Pleven, Bulgaria. Sanitas Magisterium, 2, 53-62. http://dx.doi.org/10.12738/SM.2016.1.0014 
Premature birth is associated with increased infant mortality, short and long-term negative effects on health, and additional costs for care. It is a major problem for public health worldwide (Blencove, Cousens, Oestergaard, Chou, \& Moller, 2012).

The interest of researchers in the personal characteristics and life style factors of the mothers is due to the fact that they are modifiable and they affect the incidence of premature birth (Black et al., 2008).

Pregnancy among unmarried women is associated with higher risk for premature birth (Luo, Wilkins, \& Platt, 2004). In an international survey conducted in 16 European countries in which less than $20 \%$ of couples were co-habiting found significantly higher risk for preterm labor in women cohabiting with a partner compared with married women. The risk is higher for single mothers compared to those with permanent partners (Zeitlin, Saurel-Cubizolles, \& Ancel, 2002). A population-based study in Quebec established the same results - the risk of preterm birth among mothers living in cohabitation with a permanent partner was higher, compared with married women, but lower compared to single mothers (Luo et al., 2004). The same results were observed in a cohort study in Finland (Raatikainen, Heiskanen, \& Heinonen, 2005). In Bulgaria more than $60 \%$ of newborns are born of unmarried mothers (WHO, Regional Office for Europe, 2013). In a study conducted in our country it was found there was a more than three times higher risk for having a baby with low birthweight among unmarried mothers in comparison with married mothers OR $=3.7$ (Grancharova, Georgieva, \& Alexandrova, 2008).

Many diseases of the pregnant woman lead to increased risk of premature birth, including systemic lupus erythematosus, chronic lung disease, hypertension, diabetes, heart disease, asthma, chronic kidney disease, or hypertensive conditions during pregnancy. All these disorders effect the normal placental feeding of the fetus (of oxygen and nutrients) and thereby adversely effect growth and development. Some acute conditions during pregnancy - infections, severe trauma, shock, placental abruption and others - may lead to spontaneous preterm birth (Alexieva, Marinov, Karamishev, Shopov, \& Slancheva, 2009; Savitz et al., 2005).

A study of Grancharova et al. (2008) found a significantly higher risk for having a baby with low birth weight in mothers with pregnancy complications $-\mathrm{OR}=8.8$ (Grancharova et al., 2008). Masseva et al. (2010) reported a more than seven times higher share of intrauterine infections in mothers with premature birth - $46.7 \%$ compared to women who gave birth at term - 6.7\% (Maseva et al., 2010).

This scientific study meets a need to analyze some life style characteristics of mothers, such as marital status and health of the mother, as risk factors for premature birth in Bulgaria. 


\section{Purpose}

The study aims to explore the impact of marital status and health of the mother as risk factors for premature birth in the city of Pleven, Bulgaria.

We hypothesized a positive association between premature birth and single motherhood. Furthermore, we assumed a positive link between poor health of the mother and premature birth.

\section{Method}

\section{Research Design}

A case-control study was carried out in the city of Pleven, Bulgaria between 2007 and 2013 (Kamburova, Hristova, Georgieva, \& Khan, 2014). Pleven is a typical township, located in north central Bulgaria. At the beginning of the study (2007) the population of the city was 139573 . In the same year the birth rate was $8.96 \%$. Maternal care was carried out only by the University Hospital. 2004 children were born at University Hospital, 1981 of which were live births. The proportion of preterm infants among all live births was $7.7 \%$.

\section{Target Population}

The study was comprehensive for premature children (all 58) and representative for full-term infants (192 or 10.4\% of all) born in 2007 in the University Hospital of Pleven, who resided in city of Pleven.

Cases: 58 premature infants weighing $2500 \mathrm{~g}$ or less at birth. Their gestational age was 37 weeks of gestation or less, and they resided in Pleven.

Controls: 192 term infants who were matched to premature infants by date of birth by lottery method. They weighed more than $2500 \mathrm{~g}$. Their gestational age was more than 37 weeks and they also resided in Pleven.

In order to avoid possible selection bias and to increase the accuracy and reliability of the results the group ofterm infants was higher and the ratio of the two groups of preterm and term infants was $1: 3.3$.

\section{Instruments}

Document analysis: The birth weight, gestational age and home addresses of newborns was derived from medical records in a neonatal clinic at the University Hospital of Pleven.

Interviews: The information for marital status and health of the mother was gathered retrospectively by interviewing mothers during home visits. Such information was 
not available in the records of mothers in the obstetrics ward, and not all women retained documents from antenatal visits.

Special questionnaires were designed for the purpose of the study. They are part of a larger study of risk factors for premature birth in the region of Pleven, Bulgaria. The questionnaire used for the documents analysis contained 39 questions, four of which were related to the demographic and socio-economic status of the mother. The questionnaire for the interview comprised of 92 questions, nine of which were about the factors of life style of the mother and five questions were on the health of the women.

All included mothers answered the questionnaire in the process of an interview. All data in this study was based on women's reports during the survey interviews.

\section{Ethical Considerations}

The study was conducted under the supervision of the President of IRB. The right of privacy of the studied subjects was guaranteed. Only the leading investigator had access to the identification information. Mothers who were invited to the study expressed their free will for participation.

\section{Outcomes}

We studied premature birth $(<37$ weeks completed gestation and birthweight $<$ 2500 g.) as the outcome.

\section{Determinants}

Marital status of the mothers was coded as: unmarried (including without or with partner) and married.

Health status of the mother during pregnancy was coded as: presence of complications related to pregnancy or not, presence of chronic diseases or not, conducting home and hospital treatment during pregnancy or not.

\section{Limitations}

The findings of the present study should be viewed with some limitations in mind. Firstly, reports of the characteristics of mothers were retrospective after the child was born. Secondly, because the place of study was an urban area the findings were not related to rural areas.

Thirdly, we excluded different numbers of women who were either missing information on the principal determinants of interest (marital status and health of 
the mother) or missing information on gestational age and birth weight (needed for outcome variables), but the number of missing answers were no more than five.

Obviously there is a need for more prospective studies in Bulgaria, in which such data should be collected properly and the number of observed mothers and children should be higher.

\section{Statistical Analysis}

The survey data was processed with the statistical software packages SPSS (Statistical Package for Social Sciences), version 11.5, STATGRAPHICS and EXCEL for Windows.

Parametric tests for hypotheses testing at normal and near to normal distribution of cases - $t$-test, ANOVA with post hoc tests (LSD, Tukey, Scheffe, Bonferroni, NewmanKeuls, Duncan) - and nonparametric tests in other than normal distribution of casesPearson $\chi^{2}$ - test, Mann-Whitney, Kruscal-Wallis H-test - were applied. Regression models for modeling and prediction of correlations and multiple logistic regression analyses controlled for covariates estimated the odds ratios with $95 \%$ confidence intervals of PB and LBW were used.

The results were described using tables and indicators of structure, frequency, averages, correlations etc. Percentages were used to report observed maternal characteristics.

A value of $p \leq .05$ was considered statistically significant. Using multivariable linear regression we assessed the relationships of studied determinants with outcomes. An odds ratio (OR) was calculated to determine the effect of the marital status and health of the mother as factors for preterm birth.

\section{Results}

Our study demonstrated: a more than twice increased risk of a premature birth for unmarried mothers $\mathrm{OR}=2.83,95 \% \mathrm{CI}(1.7-4.7)$; a more than three times higher probability of giving birth to a premature baby in mothers who were: ill during pregnancy $\mathrm{OR}=3.24,95 \% \mathrm{CI}$ (1.40-7.49); had complications related to pregnancy $\mathrm{OR}=3.33,95 \% \mathrm{CI}(1.8-6.19)$ and underwent hospital treatment during pregnancy $\mathrm{OR}=3.43,95 \% \mathrm{CI}(1.59-7.42)$ when compared with mothers of term infants.

Table 1 presents the distribution of basic characteristics of the participants by premature birth. The distribution of maternal characteristics varied across mothers with premature birth and term birth. 
Table 1

Percent of Population with Maternal Characteristics

\begin{tabular}{|c|c|c|c|c|}
\hline Characteristics & $\begin{array}{l}\text { All women } \\
(n=250)\end{array}$ & $\begin{array}{l}\text { Mothers with premature } \\
\text { birth }(n=58)\end{array}$ & $\begin{array}{l}\text { Mothers with term birth } \\
\qquad(n=192)\end{array}$ & $p$ \\
\hline \multicolumn{5}{|l|}{ Marital status } \\
\hline Unmarried & 32.0 & 24.2 & 34.4 & \multirow{4}{*}{.0008} \\
\hline without partner & 4.0 & 6.9 & 3.1 & \\
\hline with partner & 28.0 & 17.3 & 31.3 & \\
\hline Married & 68.0 & 75.8 & 65.6 & \\
\hline \multicolumn{5}{|l|}{ Maternal age } \\
\hline$\leq 24$ & 25.8 & 10.4 & 30.5 & \multirow{4}{*}{.002} \\
\hline $25-29$ & 27.4 & 37.9 & 24.2 & \\
\hline $30-34$ & 29.1 & 24.1 & 30.5 & \\
\hline$\geq 35$ & 17.2 & 27.6 & 14.8 & \\
\hline \multicolumn{5}{|l|}{ Per capita income } \\
\hline Lowest ( $0-125$ euro) & & & & \multirow{3}{*}{$>.05$} \\
\hline Middle (125-250 euro) & $\begin{array}{l}36.0 \\
46.4\end{array}$ & $\begin{array}{l}41.4 \\
41.4\end{array}$ & $\begin{array}{l}34.4 \\
47.9\end{array}$ & \\
\hline Highest (over 250 euro) & $\begin{array}{l}40.4 \\
17.6\end{array}$ & $\begin{array}{l}41.4 \\
17.2\end{array}$ & 17.7 & \\
\hline \multicolumn{5}{|l|}{ Birth order } \\
\hline 1 & 52.4 & 41.4 & 55.8 & \multirow{3}{*}{.0008} \\
\hline 2 or 3 & 41.2 & 41.4 & 41.1 & \\
\hline 4 or more & 6.4 & 17.2 & 3.1 & \\
\hline
\end{tabular}

Absence of husband was reported by $32.0 \%$ of women: $4.0 \%$ of them were single mothers and $28.0 \%$ had a permanent partner. The proportion of mothers with premature births who were single $(6.9 \%)$ was more than two times higher compared to single women with term birth (3.1\%).

Overall, $17.2 \%$ of women were above 35 years old. The share of older mothers was two times higher among mothers with premature birth compared to mothers with term birth.

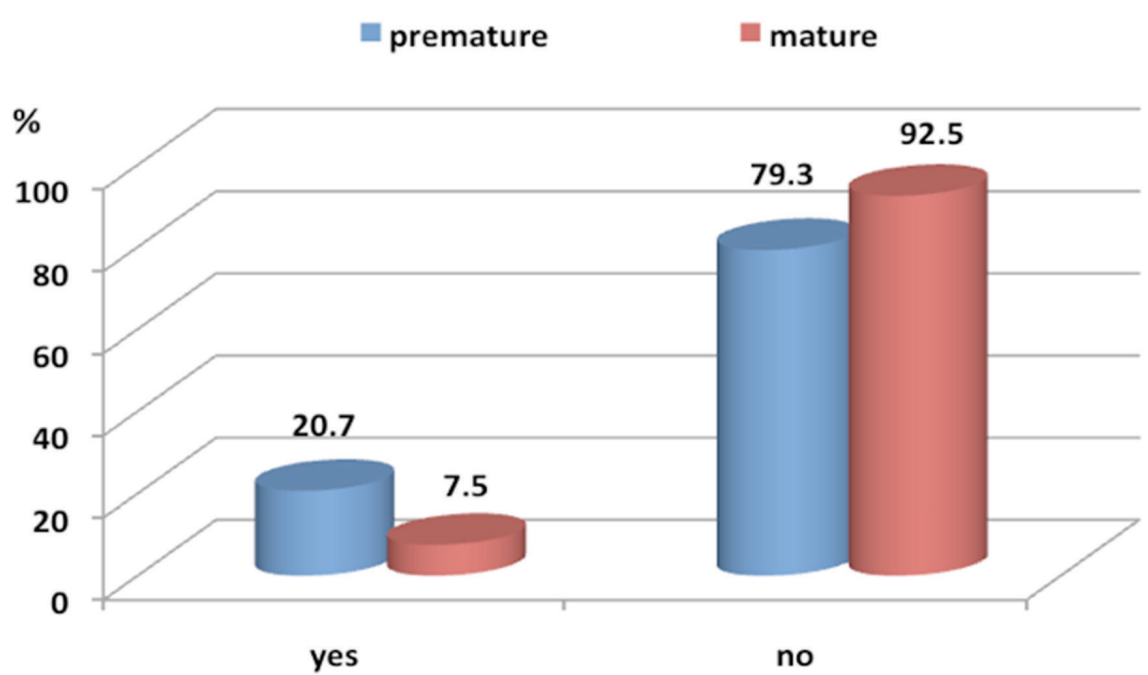

Figure 1: Distribution of preterm and term newborns according to the illness of the mother during pregnancy. 
Compered to mothers with term born infants, mothers of premature children were more likely to be single (6.9\%), above 35 years old (27.6\%) and to have delivered premature born children after the third child (17.2\%). Significant differences among mothers with premature birth were identified for marital status, maternal age and birth order.

There was no significant difference found between compared groups related to their income.

As it shown in the figure 1 the proportion of the mothers of premature children who had some disease during pregnancy $(20.7 \%)$ was three times higher compared with mothers of term infants $-7,5 \%(p=.0001 ; r=.41)$.

Almost half (51.7\%) of mothers of premature children had no health problems associated with pregnancy, while in term children one in five had complications related to pregnancy $(p=.003 ; r=.28)$. Among women with preterm children the most common complications were bleeding (17.2\%) and anemia (17.2\%).

$89.7 \%$ of mothers of premature children and $96.3 \%$ of mothers of term infants had chronic diseases. The most common disease among studied mothers was diabetes: $6.9 \%$ of mothers with premature children and $1.2 \%$ of mothers with term born children had this disease.

In both groups compared, every tenth woman underwent home treatment during pregnancy $(p>.005)$.

The proportion of mothers of premature babies who underwent hospital treatment during pregnancy $(24.1 \%)$ was significantly higher $(p=.003 ; r=.19)$ than mothers of term infants (9.4\%) (Figure 2).

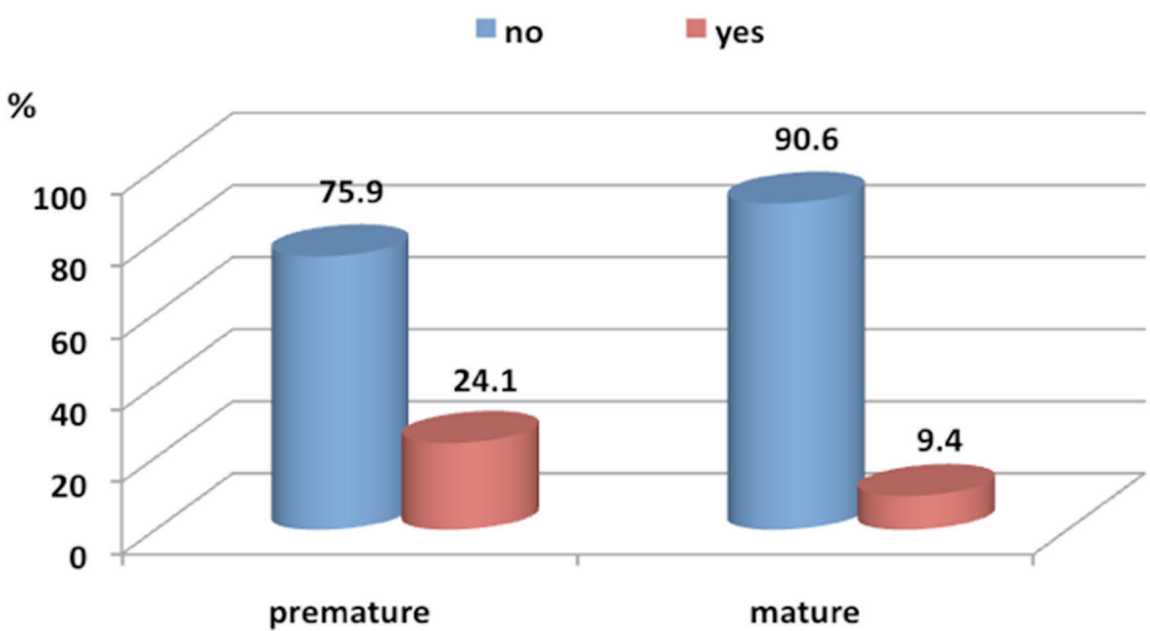

Figure 2: Distribution of preterm and term newborns whose mothers underwent hospital treatment during pregnancy. 
Table 2 shows that absence of partner, presence of disease, complications of pregnancy, and hospital treatment during pregnancy were significantly associated with premature birth.

\begin{tabular}{|c|c|c|}
\hline \multicolumn{3}{|c|}{$\begin{array}{l}\text { Table } 2 \\
\text { Maternal Characteristics Correlated with Premature Birth }\end{array}$} \\
\hline Characteristics & Premature birth & $p$ \\
\hline & OR $(95 \% \mathrm{CI})$ & \\
\hline Marital status unmarried & $2.83(1.7-4.7)$ & .0008 \\
\hline Presence of disease yes & $3.24(1.40-7.49)$ & .0001 \\
\hline Complications of pregnancy yes & $3.33(1.8-6.19)$ & .003 \\
\hline Presence of chronic disease yes & NS & \\
\hline Home treatment yes & NS & \\
\hline Hospital treatment yes & $3.43(1.59-7.42)$ & .003 \\
\hline
\end{tabular}

There were no significant differences found between compared groups related to the presence of chronic disease or home treatment.

\section{Discussion}

We have presented our research data concerning premature birth in Pleven, Bulgaria. Our results indicate that single motherhood and poor health status of mothers during pregnancy are important characteristics for premature birth.

Many authors found that the lack of a partner at birth increases the risk in terms of health of the pregnant woman and the pregnancy outcome, and in terms of the normal development of a child (Danova, 1988; Luo et al., 2004; Raatikainen et al., 2005; Zeitlin et al., 2002). The reasons for the impact of single motherhood on the outcome of pregnancy has not been sufficiently clarified, but most likely it is associated with lack of social support and limited resources among these women.

Our results confirm the negative trend in Bulgaria in terms of births to unmarried mothers $-53 \%$ of the children (National Statistical Institute Republic of Bulgaria, 2014), while Danova (1988) found a higher share of full-term children born to married women (95.6\%), and children with low weight - 79.65\% (Danova, 1988). We found an almost three times higher risk of preterm birth among unmarried mothers compared to married women - $\mathrm{OR}=2.8395 \% \mathrm{CI}(1.7-4.7)$. Such a risk is established in previous studies in Bulgaria (Grancharova et al., 2008).

We found a lower proportion of unmarried mothers who do not have a permanent partner compared with mothers living with a partner: almost $7 \%$ of mothers of premature children were without a permanent partner, while in term infants they were $3.1 \%$. The share of mothers living with partners was nearly twice as high among term infants $-31.3 \%$, compared with preterm $-17.3 \%$. Our results confirm what has been 
established in several studies, namely a higher risk for premature birth of a child among unmarried mothers or mothers without a steady partner when compared to married mothers. Also, prematurity among mothers living in cohabitation was higher compared to married women, but lower compared to single mothers (Luo et al., 2004).

Many chronic diseases of the mother (hypertension, diabetes, lupus erythematosus, etc.) are associated with an increased risk of having a premature baby (International Organization for Migration, 2007; Liu et al., 2012; Rogers \& Velten, 2011).

Our study did not establish a correlation between the presence of chronic diseases in the mother of the children in the compared groups with the birth of a premature baby, despite the high proportion of mothers with diabetes among premature infants. Mothers with diabetes were $6.9 \%$ in premature children, while they were $1.2 \%$ among term children.

On the other hand a number of diseases of the mother during pregnancy increased the risk of preterm birth (Grancharova et al., 2008). We found a three times higher probability of giving birth to a premature baby in mothers who were: ill during pregnancy - $\mathrm{OR}=3.24,95 \% \mathrm{CI}(1.40-7.49)$; had complications related to pregnancy - $\mathrm{OR}=3.33,95 \% \mathrm{CI}(1.8-6.19)$, and underwent hospital treatment during pregnancy - $\mathrm{OR}=3.43,95 \% \mathrm{CI}(1.59-7.42)$ when compared with mothers of term infants.

\section{References}

Alexieva, D., Marinov, B., Karamishev, V., Shopov, E., \& Slancheva, B. (2009). Urinary tract infections, pregnancy and disease in early neonatal period for 2007-2008. Obstetrics \& Gynecology, 48(Suppl. 2), 23-25.

Black, E. M., Allen, H. L., Bhutta, Z. A., Caulfield, L. E., de Onis, M., Ezzati, M. .. Rivera, H. (2008). Maternal and child undernutrition: Global and regional exposures and health consequences. The Lancet, 371(9608), 243-260.

Blencove, H., Cousens, S., Oestergaard, M., Chou, D., \& Moller, A. B. (2012). National, regional and worldwide estimates of preterm birth in the year 2010 with time trends for selected countries since 1990: A systematic analysis. CHERG/WHO

Danova, N. (1988). Medical and social aspects of having children with low body weight (Doctoral dissertation, Bulgaria Medical University, Sofia, Bulgaria).

Grancharova, G., Georgieva, R., Alexandrova, S. (2008). Risk factors for low birth weight in Gabrovo Regional Hospital, Bulgaria (2005-2006). European Journal of Public Health, 18(1), 200. doi: http://dx.doi.org/10.1093/eurpub/ckn504

International Organization for Migration. (2007). Preterm birth: Causes, consequences, and prevention. Washington, DC: National Academy Press.

Kamburova, M. (2014). Risk factors for premature birth of children and their impact on health and social needs in the development of children up to 3 - years (Doctoral dissertation, Bulgaria Medical University, Pleven, Bulgaria).

Kamburova, M., Hristova, P., Georgieva, S., Khan, A. (2015). Adverse effects of maternal age, weight and smoking during pregnancy in Pleven, Bulgaria. South Eastern European Journal of Public Health, (IV), 39-48. 
Liu, L., Johnson, H., Cousens, S., Perin, J., Scott, S., Lawn, J. E. ... Black, R. E. (2012). Global, regional and national causes of child mortality: An updated systematic analysis. The Lancet, 379(9832), 2151-2161.

Luo, Z. C., Wilkins, R., Platt, \& R. W. (2004). Kramer MS. Risks of adverse pregnancy outcomes among Inuit and North American Indian women in Quebec, 1985-1997. Paediatric and Perinatal Epidemiology, 18(1), 40-50.

Masseva, A., Dimitrov, A., Nikolov, A., Dukovski, A., Popivanova, P., \& Garnisov, T. (2010). Assessment of the role of some risk factors for preterm birth and benefit of screening implement. Obstetrics and Ginecology, 49(6), 3-7.

National Statistical Institute Republic of Bulgaria. (2014). Marital and extra-marital live births by districts, municipalities and place of residence. Retrieved November 05, 2014 from http://www.nsi.bg/

Raatikainen, K., Heiskanen, N., \& Heinonen, S. (2005). Marriage still protects pregnancy. BJOG: An International Journal of Obstetrics and Gynaecology, 112(10), 1411-1416.

Rogers, L. K., \& Velten, M. (2011). Maternal inflammation, growth retardation, and preterm birth: Insights into adult cardiovascular disease. Life Sciences, 89(13-14), 417-421.

Savitz, D. A., Dole, N., Herring, A. H., Kaczor, D., Murphy, J., Siega-Riz, A. M. .. MacDonald T. L. (2005). Should spontaneous and medically indicated preterm births be separated for studying aetiology? Paediatric and Perinatal Epidemiology, 19(2), 97-105.

WHO, Regional Office for Europe. (2013). Health for all database. Retrieved December 10, 2014 from http://www.who.int/en/

Zeitlin, J. A., Saurel-Cubizolles, M. J., \& Ancel, P. Y. (2002). Marital status, cohabitation, and the risk of preterm birth in Europe: Where births outside marriage are common and uncommon. Paediatric and Perinatal Epidemiology, 16(2), 124-130. 